\title{
POLÍTICAS PÚBLICAS DE EDUCAÇÃO, PSICOLOGIA E NEOLIBERALISMO NO BRASIL E NO MÉXICO NA DÉCADA DE 1990
}

\author{
PUBLIC EDUCATION POLICIES, PSYCHOLOGY AND NEOLIBERALISM \\ IN BRAZIL AND MEXICO IN THE 1990
}

\author{
Alayde Maria Pinto Digiovanni ${ }^{(*)}$ \\ Universidade Estadual do Centro-Oeste, Irati (Pr), Brasil \\ Marilene Proença Rebello de Souza $a^{(* *)}$ \\ Universidade de São Paulo, São Paulo (Sp), Brasil
}

Resumo: Este artigo procura compreender o contexto político e social do Brasil e do México que favoreceu determinadas concepções de aprendizagem e de desenvolvimento humano, produzidas pela Psicologia Educacional, presentes nas políticas educacionais, na década de 1990. Os países foram escolhidos em função de semelhanças nos dados educacionais, demográficos e em integração aos mercados globais. Utilizam-se como fontes de pesquisa produções acadêmicas sobre o tema, documentos e dados educacionais dos órgãos oficiais desses países. Conclui-se que as concepções da psicologia encontradas concebem um sujeito abstrato em consonância com a concepção de sujeito prevista pela ordem econômica proposta pelo neoliberalismo.

Palavras-chave: Políticas públicas de educação; Psicologia da educação; Neoliberalismo.

\begin{abstract}
This paper seeks to understand the political and social context of Brazil and Mexico that favored certain conceptions of learning and human development, produced by the Educational Psychology, which are present in education policies in the 1990s. The countries were chosen due to similarities in data educational, demographic and in integration to global markets. Essays on the topic, educational documents and data from official agencies of these countries were used as source for the academic research. The conclusion is that the psychology conceptions found conceive an abstract individual as designed by the economic order proposed by the neoliberalism.
\end{abstract}

Keywords: Public policies in education; Psychology of education; Neoliberalism.

(*) Mestre, aluna do curso de doutorado do Programa Interunidades de Pós-graduação em Integração da América Latina, Universidade de São Paulo (PROLAM/USP), bolsista CAPES, Professora Assistente da Universidade Estadual do Centro-Oeste, Irati/PR. E-mail: <alayde@irati.unicentro.br>.

(**) Doutora, Professora Livre-docente do Programa de Psicologia Escolar e do Desenvolvimento Humano do Instituto de Psicologia da Universidade de São Paulo (IPUSP/USP) e do Programa de Pós-graduação em Integração da América Latina da Universidade de São Paulo (PROLAM/USP). E-mail: <mprdsouz@usp.br>. Recebido em: 21.03.2014, aceito em: 27.05.2014. 


\section{INTRODUÇÃO}

A América Latina tem sido palco de discussões e de ações no campo da educação com vistas à universalização do acesso e à garantia da qualidade do ensino em todos os níveis. Nas últimas décadas do século XX, forte pressão política se estabeleceu sobre o poder público, a partir de setores organizados da sociedade, que reivindicavam o direito à educação pública, universal, gratuita, democrática, laica e de qualidade, bem como por meio de organismos internacionais de financiamento, que estabeleceram determinadas exigências aos países "em desenvolvimento", no âmbito da educação, visando seu desenvolvimento econômico e social. Essas exigências internacionais se inscrevem no cenário da globalização, que tem sua consolidação, a partir do Consenso de Washington, em 1989, promovido por diversos acordos de financiamento protagonizados pelo Banco Mundial e por relações de ampliação do mercado.

Identifica-se, neste período, a educação como um fator primordial para o desenvolvimento econômico, implicado em uma série de indicações internacionais para as políticas públicas educacionais da América Latina e Caribe. Tais recomendações se coadunam e impulsionam o modelo de orientação econômica neoliberal, e tem como um dos eixos centrais o Relatório da Comissão Internacional sobre Educação para o Século XXI, da UNESCO, coordenado por Jacques Delors (1996). Essas indicações buscam, nas Ciências Humanas e na Psicologia Educacional, concepções interacionistas de desenvolvimento humano e de aprendizagem que corroborem com princípios e finalidades do modelo econômico, que visa, por meio da educação, preparar indivíduos para esta nova ordem mundial imposta pela globalização acelerada deste período.

É no cenário da globalização, hegemonicamente neoliberal, que se constitui o objetivo deste estudo: compreender o contexto político e social que favoreceu determinadas concepções de aprendizagem e de desenvolvimento humano, produzidas pela Psicologia Educacional, e que estão presentes nas políticas públicas de educação do Brasil e do México, na década de 1990. Foram escolhidos esses países em função de semelhanças em termos de dados educacionais, demográficos e em integração aos mercados globais. Do ponto de vista metodológico, utiliza-se como fonte de dados documentos oficiais, produções acadêmicas sobre o tema, bem como dados educacionais dos dois países.

A análise partirá de uma breve incursão histórica sobre a reorganização financeira internacional, apresentando a implementação do neoliberalismo na América Latina e como a educação pública foi se constituindo, à luz deste modelo, no Brasil e no México. No âmbito dos documentos analisados, identifica-se a presença de conceitos oriundos de abordagens em Psicologia Educacional que dão sustentação teórico-metodológica às concepções de ensino e de aprendizagem que subsidiam políticas educacionais na perspectiva da sociedade neoliberal. Por fim, considera-se que as políticas produzidas e implementadas na década de 1990, se adequaram às recomendações que objetivavam um projeto educacional específico para a América Latina nesta década, elaborado pelos organismos internacionais sob as recomendações do Fundo Monetário Internacional. 


\section{NEOLIBERALISMO NA AMÉRICA LATINA}

A economia mundial depois da Segunda Guerra teve a maior expansão da história, incluindo os países que se encontravam na periferia do sistema capitalista. Isso ocorre em função da explosão demográfica que ampliou consideravelmente a força de trabalho disponível, da melhor exploração dos recursos naturais, energéticos e agrícolas e do desmantelamento dos países colonialistas, que provocou uma abertura de mercado direto com as ex-colônias e o crescimento da demanda global, que, por sua vez, promoveu a incorporação dos fatores produtivos ociosos ao processo econômico.

Para sustentar a nova ordem econômica proposta foram criados, em 1945, o Banco Internacional para Reconstrução e Desenvolvimento (BIRD) com seus dois organismos financeiros internacionais, o Fundo Monetário Internacional (FMI) e o Banco Internacional de Desenvolvimento (BID), ambos com a finalidade de regular e acompanhar as relações econômicas internacionais e a reconstrução econômica, em especial, dos países europeus ameaçados pela falta de liquidez. Outros organismos foram se somando a estes, com destaque para a Organização das Nações Unidas (ONU, 1945), a United Nations Educational, Scientificand Cultural Organization (UNESCO, 1945) e a United Nations Children's Fund (UNICEF, 1946). Outro agente importante nesse processo, de cunho financeiro, foi o Banco Interamericano de Desenvolvimento (BID, 1959), a United States Agency for International Development (USAID, 1961) e, por fim, o Programa das Nações Unidas para o Desenvolvimento (PNUD, 1965). Todos tinham a missão de auxiliar a elaboração de políticas em diferentes setores, como economia, saúde e educação, dos países atingidos pela guerra e os países latino-americanos.

Com as ações financeiras iniciais, a América Latina obteve um crescimento considerável resultante do aumento das exportações e facilidades do financiamento externo, que se constata no aumento da renda per capita que em média cresceu mais de cinco mil dólares apenas no ano de 1966 (RANGEL e GARMENDIA, 2012).

Crescimento controlado por estratégias de intervenção do Estado, porém, "el papel del Estado fue cuestionado, debido, principalmente, a que los beneficios del crescimiento no se reflejaban en la población latinoamericana" (RANGEL e GARMENDIA, 2012, p. 40). Isso fez com que no segundo período fossem mais regionalizadas as estratégias com a adoção de medidas protecionistas que buscavam dar maior equilíbrio ao desenvolvimento das regiões, porém, estas se mostraram ineficazes e terminaram por impulsionar a crise da década de 1980.

Com a falência do sistema keynesiano, acentuou-se a liberalização financeira que procurou superar a chamada repressão financeira:

(...) a partir de la desregulación de la actividad financiera local e internacional. Según se argumentaba, estas transformaciones resultarían en una mayor eficiencia en la asignación de los recursos financieros, promoviendo el ahorro y favoreciendo la inversión productiva. Este proceso generaría - asimismo - un "círculo virtuoso" de ahorro, inversión, crecimiento, empleo y desarrollo económico. (ALLAMI e CIBILS, p. 58.) 
A subida do dólar e a crise do petróleo ampliaram a dívida externa dos países da América Latina (Brasil e México estão entre os países que mais se endividaram), a inflação alta e a crise de abastecimento, dentre outros fatores, propiciaram a entrada do neoliberalismo na década de 1990. O Consenso de Washington (1989) indicava uma saída pela liberalização da economia com um modelo aberto e flexível. Nessa direção, a maioria dos países da América Latina abriram suas economias permitindo a entrada de investimentos estrangeiros em áreas consideradas, até então, estratégicas para os países. Constata-se, em toda a América Latina, uma onda de privatizações, de setores estatais importantes, como o energético e o financeiro.

Em alguns países, a opção por esse modelo se deu na tentativa de sair das hiperinflações e da crise fiscal que assolavam as economias, causando um enfraquecimento do Estado (CORSI, 2010). Variáveis diversas, particularmente o desemprego, debilitaram:

(...) a capacidade de resistência da classe trabalhadora. Não por acaso o Brasil, que viveu forte ascensão dos movimentos sociais na década de 1980, abraçou a estratégia neoliberal mais tardiamente. Sem dúvida que a adoção dessa estratégia implicou em uma reacomodação dos setores das classes dominantes, com o fortalecimento dos setores financeiros e rentistas e dos vinculados às exportações. Setores de classe fortemente articulados com o capital estrangeiro, que nunca teve solidariedade com o desenvolvimento nacional na periferia. (..) Muitos Estados nacionais se viram cada vez mais impotentes ante esses fluxos e "forçados" a submeterem-se aos ditames do capital financeiro. (CORSI, 2010, p. 27.)

Os organismos internacionais influenciaram, cada vez mais, os países latino-americanos, pressionando-os para a adesão às políticas neoliberais. Diante desse processo, estão os organismos de crédito que, ao cederem empréstimos, exigem uma contrapartida de adequação das políticas públicas para favorecerem os grandes investidores. Todas estas ações, no bojo da aceleração do processo de globalização, extrapolaram a esfera econômica da produção e finança, entrando em áreas como a educação e a cultura (CASASSUS, 2001).

Na educação pública, as intervenções mais significativas vieram a partir da Conferência Mundial de Educação para Todos, em 1990. Dentre estas agências, destacam-se a UNESCO, a UNICEF, o PNUD e o BID na implementação das ações decorrentes da conferência. Os governos que dela participaram, assinando a Declaração Mundial de Educação para Todos, comprometeram-se a assegurar uma educação básica de qualidade a crianças, jovens e adultos. Porém, a compreensão, na maioria dos casos, foi a de que para estratos sociais diferentes, o esperado eram ensinos diferentes, uma vez que se compreendia que as necessidades básicas de um e outro não poderiam ser as mesmas em países de extremas desigualdades sociais. Isso trouxe um agravamento das diferenças entre os mais ricos e os mais pobres, ficando reservado para estes uma educação focada na produtividade do mercado, dificultando o acesso a uma educação de qualidade.

Conforme Cruz (2003), estas medidas neoliberais acabaram por ocasionar sérios problemas sociais nos países: desemprego, subemprego, precarização das condições de trabalho, redução de salários, desregulamentação dos direitos trabalhistas e previdenciários, entre outros, agravados pelo desemprego estrutural, fruto do acelerado avanço tecnológico. As transformações necessárias para promover o acesso de "todos", como assinalado na conferência, ficaram longe de serem asseguradas, pois: 
(...) as agendas nacionais para a educação são formadas mais no nível do regime do que no nível estrutural; as "políticas educativas", o processo de determinar o conteúdo e o processo da educação são poderosamente moldados e limitados pelas "políticas educativas", pelo processo de determinação das funções a serem desempenhadas, pela importância do consequente provimento dos seus recursos, pelo sistema educativo como parte de um quadro nacional regulador mais amplo. De uma forma muito crítica, neste contexto, todos os quadros regulatórios nacionais são agora, em maior ou menor medida, moldados e delimitados por forças supranacionais, assim como por forças político-econômicas nacionais. E é por estas vias indiretas, através da influência sobre o Estado e sobre o modo de regulação, que a globalização tem os seus mais óbvios e importantes efeitos sobre os sistemas educativos nacionais. (SILVA, 2011, p. 05.)

Os países da América Latina passaram, então, a reformular suas leis educacionais para se adequarem ao compromisso assumido de "Educação para todos".

Foram realizadas discussões entre representantes das diferentes esferas administrativas para delinearem seus planos decenais, pretensamente em uma perspectiva participativa, além da criação dos fóruns públicos. A adequação da legislação deu-se em 1993 e 1994 no México e, no Brasil, em 1996 (CASASSUS, 2001).

Houve uma transformação na função social da escola a partir destes acordos, pois levadas em conta as indicações feitas pelos organismos internacionais, a educação passou a apresentar um objetivo mercadológico. Consequentemente, as políticas públicas de educação, sob esta ótica, priorizaram "critérios como eficiência, eficácia, produtividade - bem como conceitos de empregabilidade, competência, e conduzem a escola como obrigação de preparar para o mercado de trabalho" (GALVANIN, 2005, p. 4).

As intervenções intensificaram-se a partir do relatório elaborado por Jacques Delors, denominado Educação um tesouro a descobrir, de 1996, encomendado pela Comissão Internacional sobre Educação para o Século XXI, da UNESCO. O relatório afirma que a educação deve contemplar talentos individuais; prescreve políticas que devem ser assumidas pelos países latino-americanos assentadas em princípios neoliberais; indica alternativas educacionais baseadas em competências e habilidades, em uma perspectiva de formação para o mercado e para o pragmatismo demandado pelo capitalismo; subscreve a ideologia do capital humano e a importância do investimento educativo para a produtividade; concebe um indivíduo que se adapta e acompanha as transformações necessárias para o mundo contemporâneo para a denominada sociedade da informação; e compreende a educação como solução para os problemas da desigualdade entre os países, e entre grupos sociais, desconsiderando que a educação encontra-se no interior de um sistema político e econômico que a determina. Este relatório se caracteriza por apresentar uma concepção individualista e abstrata de sujeito. Nesse sentido, pode ser interpretado como o êxito da difusão de uma cultura neoliberal no Brasil e, sobretudo, no México, posto que é indicado como referência por suas políticas educacionais até a presente década ${ }^{(1)}$.

(1) No México, o relatório é indicado na íntegra e em diferentes documentos na página da Subsecretaria de Educación Básica acessada dia 24/09/2012, em: <http://basica.sep.gob.mx/seb2010/start.php >. No Brasil, citações do relatório são encontradas em documentos do MEC acessados dia 24/09/2012, em: <http://portal.mec.gov.br/seb/arquivos/ pdf/livrodarede.pdf > . 
O relatório Delors apresenta uma análise das condições educacionais da América Latina como um problema de desigualdade educacional e retira da discussão todo e qualquer conteúdo de classe, de forma que as desigualdades sociais são reduzidas a desigualdades educacionais e não a relações assimétricas de poder (FRIGOTTO, 2008).

O conceito principal de educação ao longo da vida é tratado como uma das chaves de acesso ao século XXI. Definem-se quatro pilares considerados fundantes da educação, o primeiro pilar aprender a viver juntos, que em suma propõe que se busquem "projetos comuns ou, então, a uma gestão inteligente e apaziguadora dos inevitáveis conflitos (...) a Comissão sonha com uma educação capaz de fazer surgir este espírito novo" (DELORS ett all., 1998, p. 19). Os outros três dos quatro pilares descritos no relatório constituem as bases conceituais que vão orientar as políticas educacionais da América Latina e do Caribe. Consideram os elementos fundamentais para aprender a viver juntos: aprender a conhecer, em que se menciona que todos devem acessar uma cultura geral que seja o passaporte para uma educação permanente; aprender a fazer, que afirma que, além da aprendizagem de uma profissão, deve-se adquirir uma competência mais ampla que prepare todos para o enfrentamento de múltiplas e variadas situações, propõe formas de alternância entre escola e trabalho; por fim, apresenta a proposição do aprender a ser, que pretende explorar todos os talentos que denominam de tesouros escondidos no interior de cada ser humano (DELORS ett all., 1998). Tais premissas traduzidas como pilares educacionais, objetivam fundamentar propostas pedagógicas apoiadas em determinadas concepções de psicologia que as justifiquem, propostas pedagógicas que visam moldar o indivíduo a esse modelo de sociedade.

As medidas econômicas e educacionais dos países são caracterizadas por proposições neoliberais, decorrentes das exigências dos organismos de crédito. Essas políticas econômicas implementadas não atingiram as metas que anunciavam e "estos cambios estimularon la vigencia de altas y volátil estas as de interés, lo que profundizó la ciclicidad en el sector externo y potenció la fragilidad e inestabilidad de la economía" (ALLAMI e CIBILS, 2010, p. 58). Isso se reflete também na educação, pois, em maior ou menor grau, tais proposições aprofundam as desigualdades educacionais e sociais constitutivas das sociedades latino-americanas e caribenhas, desde o período colonial.

\section{NEOLIBERALISMO E POLÍTICAS EDUCACIONAIS NO BRASIL}

As políticas educacionais no Brasil têm influência dos organismos internacionais, desde o período da ditadura militar, quando a USAID estabeleceu uma série de convênios de assistência técnica e cooperação financeira, na década de 1960, com o Ministério da Educação (MEC). Foram firmados doze acordos entre junho de 1964 e janeiro de 1968, abrangendo a Educação Básica e o Ensino Superior (ARAPIRACA, 1979).

Com o processo de redemocratização da sociedade brasileira, fortaleceram-se, na década de 1980, os movimentos sociais, entre eles o da educação - com ênfase em pedagogias contra-hegemônicas, na educação popular, na pedagogia crítico-social dos conteúdos e na pedagogia histórico-crítica — atuando em contraposição à educação dominante da elite brasileira, as chamadas "pedagogias da prática". Embora tenha havido 
muitos debates dos defensores destas tendências pedagógicas, houve um crescimento de um conjunto de ideias, articuladas com propostas econômicas, que propiciaram o fortalecimento do pensamento neoliberal, pós-estruturalista, com um fortalecimento da pedagogia da prática a partir da década de 1990 (SAVIANNI, 2011).

Segundo Gentilli (1995), um fato marcante foi durante o discurso do então presidente Collor, no lançamento do Programa Brasileiro de Qualidade e Produtividade em 1991, que afirmou que era necessário adquirir competitividade por meio da educação para colocar o país em desenvolvimento e desvalorizou, em sua fala, a educação pública. Ressaltou:

(...) a urgência de uma 'revolução educacional' que permitisse ao país atingir patamares de competitividade mais elevados no mercado internacional. Imersas nessa onda, as denúncias quanto à falência do sistema de ensino básico no país passaram a ancorar-se nos imperativos da modernidade a se perseguir, conforme os ditames da nova ordem econômica. (GENTILI, 1995, p. 60/61.)

No Brasil, o relatório Delors teve sua publicação em 1998 com uma apresentação do então Ministro da Educação Paulo Renato Souza, que ressaltava a importância desse documento para o cumprimento da tarefa que o MEC teria: a de repensar a educação brasileira. A mesma orientação contida no relatório vem traduzida para a educação brasileira, em 1997, com a publicação dos Parâmetros Curriculares Nacionais (PCN) que serviriam de referência para a elaboração dos currículos de todas as escolas brasileiras de Educação Básica, bem como as Diretrizes Curriculares Nacionais para o Ensino Superior. A Educação Básica e Superior no Brasil passaram a se orientar por uma educação que promove em seus alunos competências e habilidades do ideário neoliberal disseminado por diferentes tendências pedagógicas, como a pedagogia das competências, o neotecnicismo contido na "qualidade total" e na "pedagogia corporativa" (SAVIANI, 2011).

Os resultados destas ações propiciaram investimento na Educação Superior privada, promovendo sua significativa ampliação. Em 1980, eram 682 cursos com 885.054 alunos. Vinte anos depois, este número subiu para 1442 cursos com 2.428.258 matriculados. Portanto, de acordo com os relatórios estatísticos do $\mathrm{INEP}^{(2)}$ a rede privada detinha $69,7 \%$ das matrículas dos jovens e adultos neste nível de ensino em 2002. As desigualdades regionais também cresceram e se tornaram cada vez mais acentuadas. Embora tenha ocorrido um aumento de matrículas, a distribuição foi extremamente desigual: em 2003, há 3.544.920 alunos matriculados no Ensino Superior. Destes, 2.320.346 eram da região sul e sudeste, onde se concentrava a maioria dos cursos privados. A oferta pública garantiu quase metade das matrículas nas outras regiões do país.

Não se pode negar que na esteira da Educação para Todos, o Brasil universalizou as matrículas no Ensino Fundamental atingindo um percentual de aproximadamente 98\% de matrículas nesta faixa etária, auxiliada por medidas do Ministério Público, via Conse-

(2) Todos os dados retirados do INEP foram acessados em 24 de outubro de 2013 nos sites: <http://portal.inep.gov.br/ basica-levantamentos-acessar>, <http://portal.inep.gov.br/basica-censo-escolarsinopse-sinopse $>$ e $<$ http://portal.inep. gov.br/superior-censosuperior-sinopse>. 
lhos Tutelares que assumiram a tarefa de fiscalizar a garantia do direito à educação dos 7 aos 14 anos. Porém, ao se observar o índice de concluintes, percebe-se que, entre 1997 e 2002, o índice de conclusão do Ensino Fundamental aos 15 anos passou de 21,1\% para $37,3 \%$, índice muito abaixo do adequado (INEP, 1997/2002).

Em relação ao Ensino Médio, os dados demonstram que não houve avanços nas décadas de 1980 e 1990, pois a maioria dos jovens de 15 a 18 anos estava fora do Ensino Médio. Os dados das séries históricas do INEP, por sua vez, demostram que apenas uma minoria concluía o Ensino Médio nos primeiros anos do século XXI.

\section{NEOLIBERALISMO E POLÍTICAS EDUCACIONAIS NO MÉXICO}

A entrada do pensamento neoliberal no México causou profundas mudanças em suas políticas educacionais. Em 1983, antecipando-se à maioria dos países da América Latina, o governo federal incorpora a política econômica determinada pelo FMI e redimensiona os gastos com educação, o que causa:

(...) una reducción significativa de la matrícula de educación básica y reduce el crecimiento de otras modalidades. Además, en 1988 las confederaciones Patronal de México (Coparmex) y Nacional de Cámaras de Comercio (Concanaco) elaboran una detallada agenda de los cambios que deben llevarse a cabo y la presentan a la presidencia de la república. Entre sus demandas está la descentralización y apertura de la educación a los particulares, participación empresarial en la revisión de planes de estudio e investigación, inclusión de la moral religiosa en las escuelas públicas y otras semejantes. Como respuesta, en 1990 se firma un convenio sep-sector productivo que abre paso a la revisión conjunta de programas de estudio y a la participación privada en la dirección de un nuevo tipo de instituciones públicas (universidades tecnológicas); en 1992 se acuerda la descentralización de la educación; en 1993 se modifica el artículo Tercero (y el 130) de la Constitución, y se aprueba la Ley General de Educación que norma la descentralización, la evaluación y la creación de escuelas privadas. (ABOITES, 2012, p. 371.)

O acordo político realizado em 1992, denominado Acordo Nacional para Modernização da Educação Básica (ANMEB), se deu entre o governo central e os Estados mexicanos, em um período que o México se encontrava em uma conjuntura

(...) que conjugaba una crisis económica aguda (inflación de tres dígitos con estancamiento económico) y una situación política delicada para la estabilidad de México, derivada de un proceso electoral altamente competido y fuertemente cuestionado por la oposición, e nel que el Partido Revolucionario Institucional (PRI) había ganado las elecciones presidenciales con un porcentaje históricamente inusual (50,74\%). (DEL CASTILLO-ALEMÁN, 2012, p. 644.)

Ainda, conforme Aboites (2012), firma-se o Tratado de Livre-Comércio da América do Norte (TLCAN), que passa a permitir investimento estrangeiro no setor educacional. O México, que historicamente impediu durante décadas que o setor privado atuasse na educação do país, com essa medida "se pone enentre dicho la educación como responsabilidad pública (de Estado) y patrimonio social abierto a todos, y se fortalece la teoría y práctica 
de la educación como algo privado" (p. 371-372). E, por fim, em 1994, o México ingressa na Organização para Cooperação e Desenvolvimento Econômico (OCDE), o que o obrigou a levar a cabo as recomendações deste organismo para a educação (idem, 2012). Entre as exigências, havia a determinação de estimular a avaliação do sistema e dos professores e participar do Programme for International Student Assessment - PISA organizado pela Organisation for Economic Co-operationand Development (OECD).

Se establece así un pacto de amplias dimensiones con actores muy diferentes a los de las décadas veinte y treinta y e nesos años — ochenta y noventa - termina la larga etapa de 60 años de ampliación acelerada del derecho a la educación entendido como el derecho a participar en la dinámica escolar pública, libre de visiones empresariales y religiosas. (ABOITES, 2012, p. 372.)

Retiram-se da Constituição as limitações sobre as instituições privadas e religiosas e, embora seja um período em que se propaga a Educação para Todos em nível básico, que posteriormente foi ampliada para o Ensino Superior, houve uma defasagem entre as propostas e os aportes econômicos. Há uma deficiência de propostas do Estado para viabilizar tal ampliação, deixando uma ambiguidade ao que se refere ao texto da Constituição como dever do Estado garantir o direito à educação. Nesse sentido, a alteração mais significativa, e:

(...) que más directamente limita el derecho a la educación consiste en que el texto vigente hasta antes de 1993 no hacía diferenciación alguna entre modalidades o niveles educativos. Hablaba de "Art. 3ํ La educación que imparta el Estado [...]" (Reforma de 1946, en INSP, 2011), sin especificar o excluir algún tipo de escuela en particular. Sin embargo la reforma de 1993 hace que la responsabilidad de impartir educación quede reducida a la básica: "Art. 3ํㅜ [...] El Estado-federación, estados y municipios — impartirá educación preescolar, primaria y secundaria”. Nada más. Al mismo tiempo, la reforma constitucional dice que, a diferencia del Estado, "los particulares podrán impartir educación en todos sus tipos y modalidades" (INSP, 2011). En el mismo texto de 1993 se confirman las implicaciones de este cambio, pues se añade una fracción que establece que en las modalidades fuera de preescolar, primaria y secundaria al Estado no le corresponde "impartir", sino sólo "promover" y "atender". Dice: "Además de impartir la educación preescolar, primaria y secundaria [...] el Estado promoverá y atenderá todos los tipos y modalidades educativos incluyen do la superior - necesarios para el desarrollo de la nación [...]" (INSP, 2011). El uso de "impartir", por un lado, y el de "promover" y "atender", por otro, ciertamente hace difícil exigir el derecho a la educación en esas modalidades. (ABOITES, 2012, p. 373.)

O aumento de estabelecimentos privados foi mais acentuado no nível superior. Em 1991, existiam 706 unidades privadas de educação superior e, em 2002, passaram a 2.153. Na educação primária, em 1992, um total de $93,65 \%$ da população era atendida na rede pública, e, na secundária, $91,87 \%^{(3)}$. Houve uma expansão da rede privada em todos os níveis e a garantia da educação para todos ficou distante da realidade. Ocorreu

(3) OEI — Sistemas Educativos Nacionales — México 1. Disponível em: <http://www.oei.es/quipu/mexico/>, <http:// www.oei.es/quipu/mexico/\#sis>, acessados em 12/10/2013. 
uma desigualdade entre a educação ofertada e as condições de acesso da população, de maneira que a reforma no México é caracterizada como um retrocesso ao modelo conservador, denominado por Krawczyk e Vieira (2003) como uma "ruptura conservadora". Houve uma descentralização de gestão proposta pelo:

Acuerdo Nacional para la Modernización de la Educación Básica estabeleceu, entre outras providências, a transferência das unidades de educação pré-escolar, primária, secundária e normal, que estavam sob controle do governo federal, aos respectivos governos estaduais. Empreendida na década de 90, esta descentralização, denominada federalização educacional, constitui uma das mudanças mais importantes na organização do sistema educacional mexicano do século XX. Foram transferidas 68.932 escolas primárias e 9.436 escolas secundárias, ficando os Estados responsáveis pela sua administração, pela reformulação curricular e pela capacitação dos professores. O governo central, no entanto, reteve uma série de funções normativas, avaliativas e compensatórias que, de fato, permitiram-lhe exercer um forte controle sobre o sistema. (...) Tatto (1999) afirma que a reforma educacional mexicana não pode ser classificada como descentralizadora stricto sensu. Ao contrário, o governo federal reteve para si o controle dos recursos financeiros - que são apenas repassados para os estados - e das funções curriculares, deixando para as administrações estaduais apenas a administração local e alguma possibilidade de desenvolvimento de um currículo regional. A autora atribui parte da resistência em delegar responsabilidades aos estados à dificuldade do governo federal de aceitar, de fato, o poder de grupos políticos adversários. (KRAWCZYK e VIEIRA, 2003, p. 83 e 84.)

Sob tensão, protestos e greves, por fim, se instalam as determinações do FMI e da OECD, no México.

\section{POLÍTICAS PÚBLICAS DE EDUCAÇÃO E A PSICOLOGIA}

Ao se analisar a trajetória histórica da educação enquanto área de conhecimento, constata-se que foi a Psicologia que assumiu a tarefa de explicar as razões das dificuldades escolares, principalmente no que se refere à compreensão de processos de aprendizagem e de desenvolvimento de estudantes. Em distintos movimentos pedagógicos presentes no pensamento educacional brasileiro, a Psicologia foi a área do conhecimento que mais se fez presente, quer na pedagogia tradicional ou no movimento escolanovista, quer nas concepções tecnicistas ou emancipatórias de Educação (SAVIANI, 2012). Historicamente, a Psicologia que precisava ser ainda reconhecida como ciência, na virada do século XX, aparta-se da Filosofia e aproxima-se das Ciências Naturais, constituindo concepções do sujeito humano enquanto um ser abstrato, biológico ou, ainda, determinado pelo meio ambiente.

Somente a partir da década de 1980, alinhando-se a movimentos sociais na América Latina, pesquisadores da Psicologia da Educação e da Psicologia Social passam a tecer críticas a essa perspectiva e a denunciar que para a América Latina é necessário ter uma psicologia emancipatória, que promova, de fato, para todos a condição de um pensamento autônomo e crítico (SOUZA, 2010). Essa tensão entre os sistemas em Psicologia estabeleceu uma discussão polêmica e importante para a construção de uma Psicologia que desse suporte a uma educação universal e de qualidade para todos. 
A Psicologia da Educação é o campo da Psicologia que fundamenta diferentes concepções pedagógicas que se fazem presentes nas orientações internacionais para a formulação de políticas públicas de educação. Os conceitos contidos no marco das orientações para a educação na década de 1990, o Relatório Delors, documento que tem como fundamento as concepções de Psicologia que compreendem o sujeito com um ser abstrato e biológico, pressupõem o processo de ensino e aprendizagem como um ato essencialmente individual, embora haja o incentivo à participação em grupo. O relatório propõe processos pedagógicos em que o professor atua como um facilitador da aprendizagem do aluno, responsabilizando, assim, o aluno sobre seu processo de aprendizagem e subtraindo do professor a tarefa do ensino, pois parte-se do princípio de que o professor deve somente facilitar e acompanhar, uma vez que nesta perspectiva se compreende que cada um tem seu ritmo interior e seu tempo de aprender, conforme fatores internos e talentos individuais.

A definição de uma determinada compreensão neoliberal implica em uma determinada compreensão dos processos educativos e de escolarização. No Relatório Delors, a lógica neoliberal estabelece uma organização procedimental do desenvolvimento de competências e habilidades constituídas por indivíduos singulares e configura um conhecimento que tem como meta prioritária a prática, o saber fazer e o aprender a aprender, dois dos pilares indicados no Relatório.

Buscou-se um tipo de conhecimento científico que correspondesse à compreensão desse sujeito neoliberal. Destaca-se que, entre os conhecimentos da Psicologia, há muitas teorias que fundamentam tal perspectiva de sujeito, mas, no caso específico do Relatório, não está claro a que tendências ele se refere. Fazendo com que professores e comunidade escolar tenham dificuldade em compreender exatamente quais são as teorias fundantes do documento, e que modelo de sociedade e sujeito as ações educacionais propostas no relatório pretendem. No Brasil, articulam o Relatório à teoria de Piaget, em função da sua concepção biológica de sujeito, que, de certo modo, combinou com a compreensão neoliberal do Relatório, pois tanto a concepção de sujeito do neoliberalismo, como a concepção que Piaget apresenta pressupõem um sujeito biológico, abstrato, e mais, que o desenvolvimento deste se dá individualmente. No México, apropriaram-se a partir desses mesmos pressupostos, estruturando orientações específicas com encaminhamentos que não favorecem o direito à educação como um direito inalienável. Conforme analisa Newton Duarte (2001, p. 70):

(...) os intelectuais a serviço do capital internacional são mestres na utilização de um discurso repleto de termos vagos que escondem os compromissos ideológicos. Evitam a todo custo que se torne evidente a defesa da liberdade plena para o capital, existente por detrás do discurso que defende a liberdade individual e mitifica a imagem do indivíduo empreendedor e criativo. Assim, o processo de "globalização" é apresentado como um processo de desenvolvimento natural e espontâneo, devendo todos os países se adaptar a tal processo, destruindo todas as formas de controle social do mercado.

As teorias da Psicologia que fundamentam as políticas neoliberais na América Latina pensam o processo de aprendizagem sempre a partir do indivíduo. Pode-se dizer que 
a lógica neoliberal é uma lógica que sempre considera o individual sobre o coletivo. Isso $\mathrm{faz}$, como dissemos anteriormente, com que os fracassos e erros recaiam sobre o sujeito individual, e em maior ou menor grau distanciam as questões políticas, sociais e econômicas das análises sobre o sujeito e seu processo de escolarização. Em uma América Latina repleta de desigualdades estruturais, isso não contribuiu com as possibilidades de emancipação da população, ao contrário, acentuou tais desigualdades e, não raras vezes, as justificou.

As teorias da Psicologia cujas bases epistemológicas se fundamentam em concepções que consideram o sujeito histórico e social, que compreendem que a aprendizagem se processa por meio de práticas pedagógicas permeadas por práticas sociais, culturais, políticas e econômicas, e que consideram que o ato de ensinar é a função primeira do professor, e o acesso ao conhecimento sistematizado pela humanidade promove a humanização e a emancipação pela via do coletivo, que os fatores biológicos interferem, mas não se sobrepõem ao social, não comparecem neste documento internacional $\mathrm{e}$, mais que isso, foram consideradas inadequadas para o desenvolvimento das políticas educacionais tanto em documentos internacionais, quanto naqueles produzidos pelo Brasil e pelo México, na década de 1990.

\section{CONCLUSÃO}

Tendo em vista a compreensão do contexto político e social do Brasil e do México que favoreceu determinadas concepções de aprendizagem e de desenvolvimento humano, produzidas pela Psicologia Educacional e presentes nas políticas públicas de educação, na década de 1990, conclui-se que a concepção que se encontra presente nos documentos das políticas educacionais concebe um sujeito abstrato e biológico, e coincide com as orientações dos organizações internacionais e com o modelo econômico que sustenta o projeto de sociedade previsto. Destaca-se que esse projeto político para a América Latina resultou da aceleração da globalização e da entrada do neoliberalismo por meio das organizações internacionais, tendo o FMI como o principal propositor de alternativas para as políticas sociais e econômicas, entre elas as educacionais, mas esse projeto aprofundou, na década de 1990, as desigualdades em países da América Latina (CASASSUS, 2007).

O desenvolvimento social, tão almejado, foi, de fato, alcançado por apenas uma pequena parcela da população. As ideias da época difundiram a compreensão de que as desigualdades eram resultantes de desigualdades educacionais, e, no limite, individuais. E este foi o discurso adotado em todo o período de implantação dos pressupostos neoliberais na educação, e fez crer que este era o caminho a ser seguido.

A compreensão do Estado como provedor das principais políticas sociais que afetam a população foi substancialmente alterado e passaram a ser as mesmas daquelas difundidas pelo Banco Mundial (CRUZ, 2003, p. 64).

Portanto, não foi surpresa sua ação de favorecimento ao setor privado, principalmente para as instituições formadoras em nível superior; o aumento dessas é significativo em ambos os países estudados, tornando o Ensino a Distância e o Ensino Superior os grandes atrativos das empresas educacionais. 
O Estado, na implantação do modelo neoliberal, teve um papel fundamental: dar suporte ao desenvolvimento do mercado e do capital e agir com mão forte na regulação desses interesses. A educação no Brasil e no México submeteu-se diretamente aos grandes acordos internacionais que pressupunham uma educação para todos que reverberaram em regras e modos de fazer a educação por meio do desenho de políticas públicas neoliberais específicas para este objetivo nas décadas finais do século XX.

Além das regulações acerca dos investimentos, ocorreram regulações sobre as propostas curriculares fundamentadas em pedagogias neoliberais que acabaram por fortalecer um pensamento ultraindividualista promovendo uma competição individual em detrimento da organização e direitos coletivos (FRIGOTTO, 2005). Pedagogias que são fundamentadas em conceitos da Psicologia que tomam o sujeito como um ser abstrato e biológico. Organizaram-se orientações pedagógicas e curriculares com temas que precarizaram a formação em nível superior e, consequentemente, a formação básica. Tais concepções da psicologia educacional vão de encontro à possibilidade do desenvolvimento da consciência e do sentimento de coletividade.

Por fim, considera-se que as políticas produzidas e implementadas na década de 1990, no Brasil e no México, se adequaram plenamente às recomendações feitas pelos organismos internacionais que objetivavam um projeto educacional específico para a América Latina nesta década. Nesse sentido, não houve propriamente um fracasso no modelo educacional nos países analisados, mas, sim, uma consolidação de um projeto assentado em determinadas concepções das Ciências Humanas, entre elas a Psicologia, delineado pelos organismos internacionais a partir de interesses políticos e econômicos específicos, que deixaram à margem o direito a uma educação com qualidade.

\section{BIBLIOGRAFIA}

ABOITES, Hugo. El derecho a la educación en México. Del liberalismo decimonónico al neoliberalismo del siglo XXI. Revista Mexicana de Investigación Educativa. v. 17, n. 53, p. 361-389, 2012.

ALLAMI, Cecília; CIBILS, Alan. Crisis financieras y regulación: propuestas heterodoxas. Revista Política y Cultura, n. 34, p. 57-85, 2010.

ARAPIRACA, José Oliveira. A USAID e a educação brasileira; um estudo a partir de uma abordagem critica do capital humano. Dissertação de Mestrado, área de concentração: Educação. Instituto de Estudos Avançados em Educação. Fundação Getúlio Vargas: Rio de Janeiro, 1979.

CASASSUS, Juan. A reforma educacional na América Latina no contexto de globalização. Cadernos de Pesquisa, novembro, n. 114, p. 7-28, 2001.

A escola e a desigualdade. 2ª ed. Brasília: Líber Livro Editora, UNESCO, 2007.

CORSI, Francisco Luiz. Crise do capitalismo e reestruturação da economia mundial. As estratégias de desenvolvimento na América Latina. Anais do XXX Encontro da Associação Portuguesa de História Econômica e Social, Lisboa, novembro, 2010.

CRUZ, Rosana Evangelista da. Banco Mundial e política educacional: cooperação ou expansão dos interesses do capital internacional? Educar, Curitiba, n. 22, p. 51-75. Editora UFPR, 2003.

DEL CASTILLO-ALEMÁN, Gloría. Las políticas educativas en México desde una perspectiva de política pública: gobernabilidad y gobernanza. Revista Internacional de Investigación en Educación, v. 04, n. 09, p. 637-652, 2012. 
DELORS, Jacques et al. Learning: the treasure within; report to UNESCO of the International Commission on Education for the Twentyfirst Century (highlights). Paris: UNESCO, 1996.

DUARTE, Newton. Vigotskie o “aprender a aprender": crítica às apropriações neoliberais e pós-modernas da teoria vigotskiana. 2. ed. rev. e ampl. Campinas: Autores Associados, 2001.

FRIGOTTO, Gaudêncio. Qualidade e Quantidade da Educação Básica no Brasil: Concepções e Materialidade. Sinproeste, 2013. Disponível em <http://www.sinproeste.org.br/wpcontent/ uploads/2013/04/A-QUALIDADE-DA-EDUCAC\%CC\%A7A\%CC\%83O-BA\%CC\%81SICA.-TETXO-PARA-A-ESCOLA-DE-GOVERNO-.-SANTA-CATARINA..pdf>.

. Educação Básica e a relação quantidade e qualidade. Cap. IV do Relatório de Pesquisa. Rio de Janeiro. UERJ. CNPq - 2008.

GENTILLI, Pablo. (org.). Pedagogia da Exclusão: crítica ao neoliberalismo em educação. Petrópolis: Editora Vozes, 1995.

KRAWCZYK, Nora Ruth; VIEIRA, Vera Lúcia. A reforma educacional no México e no Chile: apontamentos sobre as rupturas e continuidades. Educar, Curitiba, n. 22, p. 77-98, Editora UFPR, 2003.

RANGEL, Rubí Martinez; GARMENDIA, Ernesto Soto Reyes. El Consenso de Washington: la instauración de las políticas neoliberales en América Latina. Revista Política y Cultura, México, n. 37 , p. 35-64, 2012.

SAVIANI, Dermeval. Escola e Democracia. 42. ed. São Paulo: Editora Autores Associados, 2012.

SILVA, Ruth da. Educação das crianças no contexto da reforma educacional brasileira dos anos 90: uma perspectiva para além do capital. V Encontro Brasileiro de Educação e Marxismo, Educação e Emancipação Humana, UFSC, Florianópolis, 2011.

SOARES, Maria. Banco Mundial: políticas e reformas. In: TOMMASI, Lívia Di; SOUZA, Marilene Proença Rebello de. Psicologia Escolar e políticas públicas em Educação: desafios contemporâneos. Em Aberto, Brasília, v. 23, n 83, p. 129-149, 2010. 